\title{
Infografías para la difusión sobre el rol de la mujer: Pictoline, 2019
}

\section{Infographics for the dissemination about the role of women: Pictoline, 2019}

INFORMACIÓN DEL

\section{ARTÍCULO}

Fecha de recepción: 23 de Septiembre de 2021.

Fecha de aceptación: 18 de Noviembre de 2021. $\overline{1 \text { Doctora en Educación, Universidad }}$ Virtual Hispánica de México. Docente-investigador, Benemérita Universidad Autónoma de Puebla México.

E-mail: paola.rivera@correo.buap.mx Código ORCID:

https://orcid.org/0000-0002-8050-3585

2 Doctora en Administración y Gestión Estratégica, CISDE Puebla. Docenteinvestigador, Benemérita Universidad Autónoma de Puebla - México.

E-mail: melva.navarro@correo.buap.mx Código ORCID:

https://orcid.org/0000-0002-3302-1989

CITACIÓN: Rivera, P., \& Navarro, M. (2021). Infografías para la difusión sobre el rol de la mujer: Pictoline, 2019. Podium, 40, 143-162.

doi:10.31095/podium.2021.40.9

\section{ENLACE DOI:}

http://dx.doi.org/10.31095/podium.202 1.40 .9

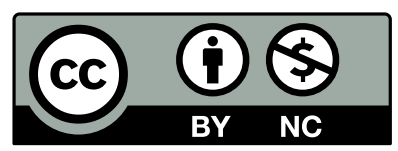

Paola Eunice Rivera Salas ${ }^{1}$, Melva Guadalupe Navarro Sequeira ${ }^{2}$

\section{Resumen}

Este artículo tiene por objeto describir el uso de la infografía para difundir mensajes sobre el rol de la mujer en el sitio oficial de la empresa Pictoline en Facebook. Se aplicó un enfoque cuantitativo, descriptivo, transversal y no experimental. Se hizo un censo mediante una guía de observación con los infográficos que trataron la temática del rol de la mujer publicados en 2019 por Pictoline en Facebook. La mayoría de las infografías tienen una estructura que facilita la difusión de los contenidos sobre el rol de la mujer y están respaldadas por fuentes confiables. Estos elementos gráficos propician una gran interacción social y entusiasmo entre los usuarios a partir de su publicación. Se concluye que el desarrollar investigaciones de este tipo permite dimensionar las audiencias en ambientes digitales para diseñar mensajes más efectivos en el tema de empoderamiento de la mujer, ya sea con fines comerciales o sociales.

\section{Palabras Clave:}

Infografia, rol de la mujer, redes sociales, interacción social, difusión de información, Pictoline.

Clasificación JEL: Z13.

\begin{abstract}
Describe the use of infographics to spread messages about the role of women on the Pictoline company's official Facebook site. A quantitative, descriptive, transversal, and non-experimental approach was applied. In addition, an observation guide was applied on infographics census that dealt with the issue of the role of women published in 2019 by Pictoline on Facebook. Most infographics have a structure that facilitates the dissemination of content on the role of women and is supported by reliable sources. Furthermore, these graphic elements promote significant social interaction and enthusiasm among users from the publication of them. In conclusion, it is considered essential to develop research of this type that allows the size of audiences in digital environments to design more effective messages on the issue of women's empowerment, whether for commercial or social purposes.
\end{abstract}

Keywords:

Infographic, role of women, social networks, social interaction, information dissemination, Pictoline.

JEL Classification: Z13.

$$
143
$$

PODIUM No. 40, Diciembre 2021, pp. 143-162

(C) Universidad Espíritu Santo - UEES

ISSN: 1390-5473 e-ISSN: 2588-0969 


\section{Introducción}

La comunicación humana, desde sus inicios, tiene como soportes para los mensajes a las infografías. Desde los jeroglíficos egipcios, pasando por apuntes de destacados inventores, como el propio Leonardo Da Vinci en sus famosos cuadernillos, incluso, aquellos bocetos sencillos que se apreciaban en medios impresos como los pasquines se buscaba explicar con la ayuda de gráficos, los acontecimientos de la época. Así, la infografía ha sido un recurso comunicativo que se ha utilizado a la lo largo de la historia. Uno de los infográficos más famosos y pioneros de la humanidad, es el elaborado precisamente por una mujer, la enfermera Nightingale, para explicar a otra mujer, la reina Victoria, sobre las causas de la mortalidad del ejército en el Este. Nightingale, expuso de manera sintética dicha problemática, a través de un infográfico, las bajas que se producían en tiempos de la Guerra de Crimea. Esta fue una de las primeras muestras del uso de estadísticos, plasmados en un mapa, con el fin de explicar un problema social (Aceves, 2016).

Esta investigación muestra una aplicación de los infográficos para la difusión en redes sociales, de una temática de importancia social $y$ cognitiva, y que ha cobrado visibilidad en los tiempos recientes, como es el rol de la mujer. El tema ha sido tan relevante que, organizaciones con fines de lucro lo han abordado, como parte de su imagen y responsabilidad social. Tal es el caso de las publicaciones hechas por la empresa Pictoline, una compañía de mercadotecnia de origen mexicano; entidad que desde su creación en 2015 se ha distinguido por comunicar temas de relevancia social de habla hispana, mediante medios electrónicos con un alto impacto en usuarios digitales. Cabe señalar que, la investigación se centra en México, puesto que desde 2019, se han detonado una gran cantidad de manifestaciones y movimientos a favor de la mujer -como 9M, la marea verde contra el aborto o el performance "Un violador en tu camino"-. Asimismo, esta ola de denuncias, ha alzado la voz en contra de los altos niveles de femicidios que se registran a nivel nacional. Las estadísticas de organismos internacionales señalaban que, en todo el territorio mexicano, eran privadas de la vida entre 9 y 10 mujeres cada día durante el año en cuestión (Galván, 2019). Teniendo este punto de partida en cuenta, a continuación, se abordan los conceptos clave de esta investigación.

\section{Revisión de literatura}

\section{La infografía}

La infografía es una herramienta gráfica que permite difundir información de manera sencilla, proporcionando datos relevantes para el receptor, que incluyen un balance adecuado entre imágenes y texto. Diversos autores (Bucchi y Saracino, 2016; Zárate y RodríguezRodríguez, 2017; Rivera-Salas, 2019) han definido este recurso informativo, y en la actualidad se reconoce su gran potencial, debido a que por sus características puede ser socializada en medios de comunicación masiva. Adicionalmente, este recurso ha tenido 
un gran impacto en ambientes digitales por su alcance a los públicos que tienen pocas posibilidades de leer contenidos extensos, ya sea por sus competencias, o bien, por la falta de tiempo que disponen para consultar contenidos informativos (Herrero y Rodríguez, 2015). El infográfico requiere la construcción de mensajes creativos, que llegan a grupos de receptores muy bien delimitados. Asimismo, la infografía es consultada y redistribuida por distintos emisores para difundir de forma innovadora, una enorme gama de temáticas que van desde la nota del día, hasta especificaciones sobre el uso de tecnología en áreas de conocimiento muy especializadas.

La infografía se percibe como una nueva manera de comunicación, ya que engloba datos en esquemas, que a su vez se colocan en infogramas organizados en un sentido jerárquico, y que, en conjunto, exponen información concisa, novedosa e incluso desconocida. Por ello, Aceves (2016) señala la importancia de evitar que la construcción de este producto comunicativo se base en subjetividades o datos no corroborados. Más aún, hay una clara tendencia de incluir este tipo de recursos para la difusión de mensajes, ya que facilitan la definición de conceptos y el desglose de información, valiéndose de elementos con atributos visuales, que son significativos para el lector, logrando que haya una mayor retención de lo que el receptor percibe (Bucchi y Saracino, 2016; Tejedor-Calvo, Portalés-Oliva y Pueyo, 2018). En cuanto a su estructura, los elementos que integran una infografía para su elaboración correcta han sido tema de diversas investigaciones. No obstante, muchos autores (Aguilera, y Velazquez, 2017; Herrero y Rodríguez, 2015; Rivera-Salas, 2019; Zárate y Rodríguez-Rodríguez, 2017) concuerdan en que este producto comunicativo debe incluir datos verificados, dirigirse a una audiencia limitada, un mensaje bien definido y fuentes que apoyen la validez de la información expuesta. Las características básicas de este elemento se ven sintetizadas en la Figura 1.

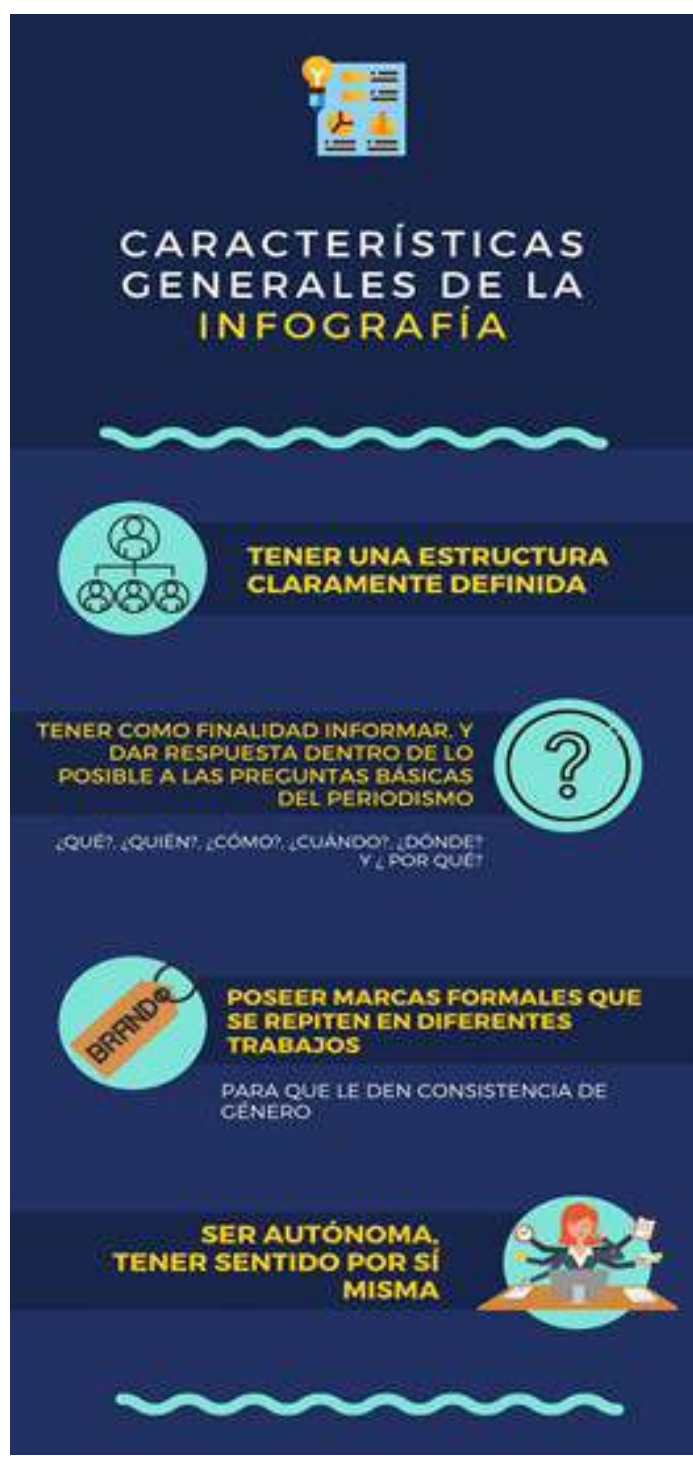

Figura 1. Características generales de la infografía. Fuente: Elaboración propia basada en Arévalo (2018). 
No hay que dejar de lado que, la infografía requiere de una visión artística y estética, traducida en un diseño que combine íconos y tipografía, distribuidos en un espacio determinado, que sea entretenida y concisa (Arévalo, 2018; Aguilera y Velazquez, 2017). Muchas veces se auxilia de varias tipografías en un mismo producto comunicativo, para distinguir los infogramas, y dar cierta jerarquía y fluidez a los componentes del infográfico para su lectura. Se habla entonces de una mezcla de colores en distintas tonalidades y diversas formas bien organizados, de manera que capte de forma inmediata la atención de lectores y ciberlectores (Aceves, 2016).

Para la elaboración de una infografía, los autores (Aceves, 2016; Arévalo, 2018; Ramos-Flores, 2019) recomiendan tener la mayor cantidad de información posible sobre el tema a exponer. Luego, se jerarquiza y se escoge aquella que es esencial para transmitir un mensaje; esta elección, implica a su vez una elección de los elementos visuales -como gráficos, mapas, iconos, entre otros, que facilitarán la representación del mensaje-. Posteriormente, se hace un boceto con los distintos módulos o infogramas que se quieren incluir como parte de una secuencia lógica del mismo producto comunicativo. Cada módulo debe ser capaz de comunicar claramente por sí mismo, como una idea secundaria, y al mismo tiempo contribuir a la idea general del infográfico (Aguilera y Velazquez, 2017). De tal manera que, hay un inicio, un desarrollo $y$ un desenlace $o$ conclusión, concretando una la estructura que expone una temática completa
(Rivera-Salas, 2019).

\section{Infografia y redes sociales}

En los últimos años ha habido un crecimiento exponencial de la penetración de las redes sociales, pues han alcanzado un gran protagonismo en el ecosistema comunicativo mundial que hospeda el ciberespacio (Tejedor-Calvo et al., 2018). Así, las nuevas dinámicas de comunicación, que incluyen la interacción por los llamados medios sociales, han favorecido a que internet sea un espacio de entretenimiento, información, conquista y casi cualquier otro uso inimaginable por el humano. Las redes sociales se han posicionado en gran medida porque han dado la posibilidad a muchos usuarios de aplicar su derecho de libertad de expresión, exponiendo temáticas que en otros espacios de comunicación masiva no serían considerados o escuchados (Ozuna y Rivas, 2014); al contrario, se han formado espacios específicos para audiencias interesadas en dichas temáticas que hacen intercambio de información a lo largo y ancho del planeta. Las publicaciones que en estos espacios colaborativos se observan denotan la capacidad de los prosumidores de generar contenidos, propios o producto de una colaboración, que se traducen en distintos formatos -solo texto, visual, audio, o audiovisual- de gran alcance.

La alta proliferación de las redes sociales supone un salto cualitativo que ha potenciado los modos de comunicación y generación del 
conocimiento que actualmente se tienen. De esta forma, el uso de redes sociales dejó de ser una moda. Han dado lugar a cambios significativos en los patrones de comunicación hasta ahora conocidos; en muchos casos, las redes sociales han apoyado al abordaje crítico y reflexivo de múltiples tópicos, así como de los propios canales y medios informativos existentes (Fuster-Guillén, SerratoCherres, Gonzales, Goicochea, y Guillén, 2020). Es decir, estamos ante un canal de comunicación con funciones de informar, vigilar y verificar lo que se informa. Todo ello, no sólo realizado por quienes administran los espacios de intercambio, sino por usuarios con características variadas y que no siempre atienden a intereses comerciales o fines de lucro.

Uno de los elementos que más ha encajado en las redes sociales son los del tipo visual -vídeo, gifs, fotografía, fotografía 360 grados, entre otras-, por la forma en que sintetizan la información que contienen. En este marco de acción, la infografía resulta ser un instrumento muy idóneo para que gran cantidad de datos lleguen de manera directa y fluida a millones de usuarios (Aguilera y Velazquez, 2017). El éxito de una infografía en espacios de socialización digital se debe a que convence racionalmente al lector, al tiempo que hace contacto con su lado emocional, propiciando a que interactúe en el ciberespacio, ya sea compartiendo o retroalimentando (Aceves, 2016). En este sentido, la conversación que ha generado la infografía ha dado pie al análisis de la comunicación social que se tiene entre usuarios en publicaciones de dominio abierto o en espacios creados por grupos que comparten intereses similares (Candale, 2017). Los resultados han sido de gran utilidad para el campo de la Comunicación y la Mercadotecnia, áreas que caracterizan mejor a los emisores y receptores con esta fuente continua de interacciones. Es así como los ambientes digitales brindan los insumos necesarios para el diseño de estrategias de comunicación más eficientes enfocadas en audiencias de gran volumen, pero con un perfil muy homogéneo (Cohen, Dengate, Morrell, y Lee, 2019; Franch y Yeste, 2017).

Por todo esto, las redes sociales son considerados medios de difusión, con mayor alcance que los medios tradicionales, logrando flujos de comunicación multidireccionales, sobre una infinita cantidad de temas, en un entorno cambiante y dinámico, pero que se encuentra al alcance de los lectores a través de dispositivos electrónicos de bajo costo (Rivera-Salas, 2019). La infografía se coloca de forma conveniente en este escenario, pues no sólo se socializa rápidamente, sino que se visualiza con facilidad y no ocupan gran cantidad de espacio en la memoria de dichos dispositivos. Así pues, juega un papel importante en la democratización del conocimiento, vertiendo mensajes que son revisados, analizados, compartidos dentro y fuera de la red social en que se publican (Garavito, 2014), y que alcanzan hasta otros usuarios $y$ prosumidores que no necesariamente están asociados a un espacio virtual, para continuar con su difusión sin censura o línea editorial a seguir. 
Como se aprecia, las redes sociales constituyen un espacio que beneficia al envío de mensajes, a través, de recursos visuales como los infográficos, mismos que se consumirán por ciudadanos de distinto estrato social, haciendo de este un contenido viral; logrando además adaptarse a los sistemas de comunicación multimodal que existen en el ecosistema digital (Tejedor et al., 2018). Por lo tanto, es un canal indispensable y con un gran potencial que reconocer para la socialización de temáticas, mediante infográficos, que pueden influir de forma positiva en la sociedad.

\section{El rol de la mujer y su empoderamiento}

La mujer, tradicionalmente entendida como cuidadora del hogar, de los de los hijos, de los padres y de quien necesite su auxilio, ha ido modificando su papel en el entorno social, desde su salida del hogar a trabajar, hasta el ocupar puestos de política relevantes, entiéndase convertirse en presidenta, ser partícipe de la economía o desempeñarse en actividades antiguamente pensadas únicamente para los varones Entonces, la mujer, como pilar material y abstracto del núcleo social que es la familia, ha tenido un camino de lucha en su visibilidad fuera del hogar (Fernández-Tijero, 2016; Guerrero y Arana, 2019). En tiempos recientes, movimientos feministas y de empoderamiento femenino, son una constante en los medios de comunicación masiva y redes sociales (Bonavitta, De Garay y Camacho, 2015; Martínez, 2017). Se ahondará un poco en estos conceptos a continuación.
El feminismo es definido por la Real Academia Española (2021) como "el principio de igualdad de derechos de la mujer y el hombre así como el movimiento que lucha por la realización efectiva en todos los órdenes del feminismo"; en cambio, el empoderamiento es un proceso personal y diferente pues cada uno tiene su experiencia propia y única de la vida, de este modo se trata de un procedimiento complejo que involucra elementos contextuales como el espacio geográfico, y estructurales -cultura, niveles educativos, costumbres, tradiciones- que en cierto modo moldean de manera indeterminada elementos que impulsan o inhiben el proceso de empoderamiento femenino (López, Valencia y Díaz, 2019).

Para fines de este estudio, el foco se centra en el empoderamiento femenino, por lo que se plantea reconocerlo como un proceso atravesado y alimentado por la construcción colectiva. Sin omitir, que refuerza perspectivas históricas del feminismo y que sigue construyendo en el día a día de los momentos políticos y sociales. El término polémico y polisémico, ha encontrado cierta convergencia entre los resultados y los debates clásicos por la necesidad de la inserción del debate de género en las prácticas del empoderamiento femenino (Saldanha y Gonçalves, 2016). Además, el concepto empoderamiento femenino ha sido altamente criticado por aprehensiones parciales; desde la óptica de no reclamar poder, sino reconocimiento a lo que la mujer en sí es y debe representar en la sociedad que es básicamente, lo mismo que es $\mathrm{y}$ representa el hombre. 
Así, retomando el papel que la mujer ha tenido que pelear por lograr tener fuera del entorno del hogar y ser reconocida en otros aspectos como lo son los económicos, políticos y sociales es lo que hace necesario el hablar de empoderamiento; en el que se refiere a una noción de poder que trasciende la esfera política formal y abarca el campo social de la vida cotidiana, al acceso a los recursos materiales y culturales de una sociedad, a la capacidad de asumir liderazgo e influencia en decisiones públicas y aquellas de corte privado que inciden sobre la calidad de vida a nivel individual (Cañedo-Cázarez y MendozaGuerrero, 2017).

Como lo señalan Ramírez, Martínez y Calderón (2016), el empoderamiento deviene del desarrollo de habilidades, y las exigencias del respeto de los derechos que tienen los individuos. Este empoderamiento implica confianza en el propio individuo; pero que demanda, la gestión de redes, la implementación de normas y la credibilidad en las instituciones, para superar las brechas que existen por condición de género. Además, el empoderamiento femenino es un concepto multidimensional, difícil de medir y fuertemente influenciado por el contexto y la capacidad del individuo de elección, que dificulta aislar su efecto (Castillo, 2019). Es decir, un empoderamiento no sólo individual sino colectivo, el cual hace alusión al conjunto de capacidades de las mujeres para enfrentar como género la problemática de género (Pérez, Rábago, Guzmán, y Zamora, 2018), lo que también propicia la posibilidad de tener referentes sociales que den testimonio vivo del mismo.

Es así como las mujeres, al reconocerse como sujetos singulares frente a los retos que propone la cotidianidad, se configuran como un sujeto político y social. La libertad se hace presente al entender que tanto hombres como mujeres tienen la tarea de transformar el mundo a través de sus acciones. Aunque históricamente se refleje una tendencia a la exclusión de la mujer, hoy en día esto ha cambiado hasta el punto de que las mujeres se integran a grupos e instituciones como líderes, agentes de cambio y de transformación, que a través de sus acciones empoderan a otras mujeres, permitiendo que muchas de ellas salgan de la opresión, en la cual se encontraban debido al sistema de creencias que les impedía alcanzar sus metas y hacer valer su voz en los contextos en que se movían (Velandia, 2016).

Infografía como difusora del rol de la mujer y su empoderamiento

Es preciso recordar, como explica De Fontcuberta (1994) que el género fue el primer elemento de segmentación en medios, y esto no es casualidad, pues representa aceptar su poder de consumo y relevancia en el tejido social. El retrato de la mujer en los medios de comunicación masiva y social tiene responsabilidad e incidencia en la creación, la modificación y el mantenimiento de juicios, prejuicios y estándares. Esto quiere decir que al intentar fomentar la equidad de género $\mathrm{y}$ el empoderamiento de las mujeres -o derechos humanos por mencionar otra 
instancia de interés-, no basta con publicar lineamientos o datos, lo cual está muy bien, pero hace falta más. Hay que subrayar que, cumplir una norma no es meritorio, es lo mínimo que se espera en la normalidad (Aceves, 2016).

El conocimiento de todo lo anterior, resulta de vital importancia para saber de buena tinta los niveles de autoconciencia en las mujeres respecto a las imágenes y estereotipos que sobre ellas mismas proyectan los medios masivos. En este contexto, algunos medios utilizan la imagen de la mujer de manera distorsionada y degradante, para inducir el consumo de una amplia diversidad de productos superfluos. Además, hacen una detallada descripción de cómo las mujeres buscan y logran "politizar" -influir- de manera informal las redes e instituciones comunitarias, dado que se les niega la participación en el gobierno local (Sancho, 2021). No obstante, en la actualidad prevalece el encuentro entre mujeres en espacios que abarcan reuniones para pensar el mundo, entenderlo, criticarlo e incidir en su transformación (Velandia, 2016). Mediante el proceso de empoderamiento de los individuos o grupos más impotentes y marginados se dan cuenta de la función de la dinámica del poder dentro del contexto de sus vidas; desarrollan habilidades y capacidades para mejorar el control sobre sus vidas; el cual puede ser ejercido sin perjudicar los derechos de los demás. Apoyar el empoderamiento de un individuo en una comunidad para la transformación de su entorno, tomando en cuenta sus necesidades y aspiraciones, es una acción que trasciende más allá del propio individuo, teniendo una significativa incidencia en quienes lo rodean (Banda, Morales y Vanegas, 2015).

Los medios y productos comunicativos son espacios adecuados para la promoción del empoderamiento. Es sabido que algunas aplicaciones de infográficos en ciertas muestras han demostrado que dan lugar a la reflexión y al replanteamiento de las ideas sobre los temas de género. Zárate y RodríguezRodríguez (2017) mencionan que el trabajo con este tipo de recursos apoya en los cambios de discursos cotidianos, propiciando interacciones menos discriminatorias, con tonos más inclusivos y equitativos lo que implica que en el mediano y largo plazo, un impacto directo en la relación que los individuos -mujeres y hombres- tienen con sus grupos más directos, $\mathrm{y}$ en un segundo plano, con su propia comunidad. Aunado a ello, la infografía se constituye como un elemento comunicativo que permite socializar a los receptores información sobre temas de género de una forma más asequible a las audiencias para que estén más familiarizados con las problemáticas. Sólo así, se podrá concientizar y lograr un impacto en los públicos (Aceves, 2016; Ramos-Flores, 2019).

Dados los elementos expuestos con antelación el objetivo de esta investigación fue: Describir el uso de la infografía para difundir mensajes sobre el rol de la mujer en el sitio oficial de la empresa Pictoline en Facebook durante 2019. 


\section{Metodología}

La investigación es de tipo cuantitativo debido a que se obtuvieron datos numéricos que permiten establecer la frecuencia con que aparecen las variables e indicadores de interés. Al ser únicamente una exposición de cómo se presentan el fenómeno de la infografía sobre el rol de la mujer en Pictoline, la investigación es descriptiva. Asimismo, se recuperaron los datos durante el segundo semestre de 2020, y no se realizó ninguna incidencia o alteración a las variables de interés, por lo que esta comunicación es transversal $\mathrm{y}$ no experimental.

La información que se recabó del sitio Pictoline, implicó un seguimiento del año 2019, periodo en el cual esta empresa de mercadotecnia generó diversos productos comunicativos en el formato de infografía, refiriendo a los movimientos que se suscitaron en México con respecto a las féminas. Es necesario puntualizar que, se consideró este año, pues fue un periodo en que se dieron a conocer diversas manifestaciones en Latinoamérica y concretamente en México, como el 9M y otros movimientos que se le conocen como la ola feminista, que han puesto en la opinión pública este tema como parte de la discusión cotidiana y la agenda mediática (Redacción Gatopardo, 2019). Para compilar toda la información posible, y considerando el tamaño de la población -el número total de infográficos relativos al tema-, se realizó un censo, ya que se incluyeron a todas las infografías que retomaron el tema de rol de la mujer durante el periodo mencionado. Esto implicó un total de 35 infográficos.

La información se recolectó mediante una guía de observación que fue construida a partir de las dos variables de investigación:

a. Infografía, entendida como el producto comunicativo integrado por un balance adecuado de imágenes y texto, que por su estructura permite difundir mensajes de diversa índole en cuestión de segundo.

b. Rol de la mujer, plasmado en letras, imágenes y atributos del género femenino o su interpretación desde la vista de otro, mujer u hombre.

El instrumento de observación incluyó un total de 70 ítems, derivados en primera instancia, de la revisión bibliográfica previa que se realizó sobre ambas variables de interés. En un segundo momento, durante el primer semestre de 2020, se realizó la validación del instrumento de investigación a través de un panel de expertos, mediante el la Razón de Validez de Contenido (RVC). Al ser 10 panelistas los que validaron el instrumento, se aceptó a todos los ítems cuya RVC fuese igual o mayor a 0.62 , como lo marca Lashew (1975). Posteriormente, durante el mes de junio de 2020, se capacitó a un par de observadores para aplicar la guía en infográficos similares, quedando listos los evaluadores, hasta el momento que tuvieron un $95 \%$ de coincidencia entre los valores registrados por ambos. Para cada 
infografía se evaluaron elementos que se integraban en su contenido; la Figura 2 permite ver algunas de las características que se consideraron en este estudio.

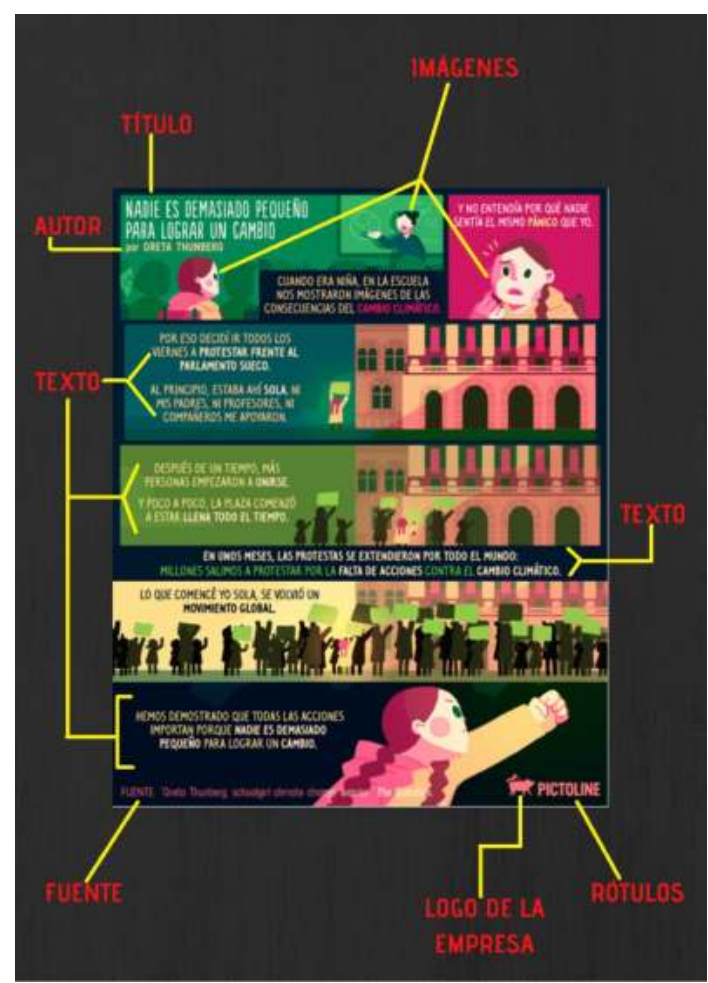

Figura 2. Ejemplo de infografía publicada por Pictoline: Nadie es demasiado pequeño para lograr un cambio.

Fuente: Elaboración propia con la infografía recuperada de Pictoline (2020a).
Adicionalmente, se dio seguimiento a los productos comunicativos en las distintas redes que son socializados por la empresa. La Figura 3 precisa la forma en que se ve socializada en el espacio virtual colaborativo que se revisó, en este caso Facebook. Es importante hacer mención que, los infográficos que se incluyeron en esta evaluación son publicados en todas las redes sociales mencionadas; no obstante, sólo se dirigió la observación en la red social indicada, en virtud de que, en México, durante 2019, dicha red es la que presentó el mayor flujo de cibernautas, alcanzando al 99\% de estos (Statista, 2020).

Una vez que se concentraron los datos, se dio un tratamiento estadístico descriptivo a los datos recabados, mediante la paquetería STATA, con el fin de obtener gráficos y tablas que permitieran atender al objetivo planteado para esta investigación.

\section{Resultados}

Del total de 35 infografías observadas, el $14 \%$ de los productos

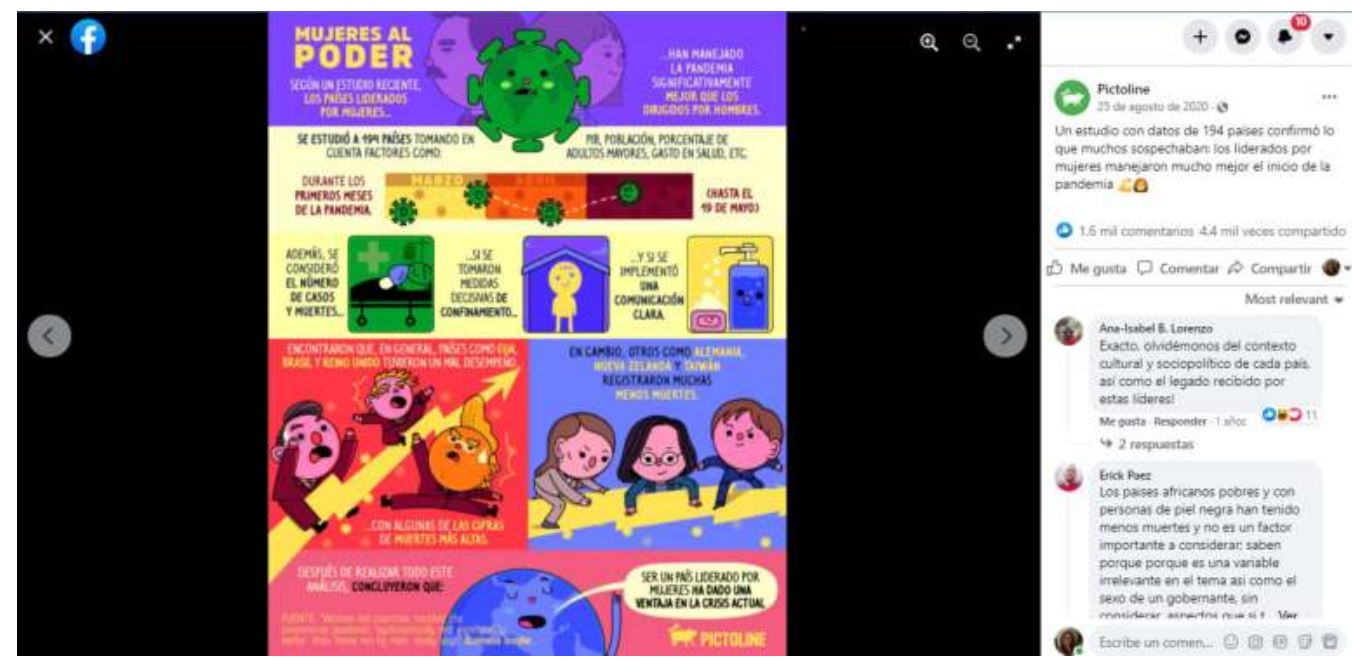

Figura 3. Infografías de Pictoline socializadas en Facebook.

Fuente: Tomada del sitio oficial en Facebook de Pictoline (2020b). 
comunicativos tuvo un patrocinio para ser publicado. El $97 \%$ de ellas fue publicada por la empresa Pictoline en su sitio oficial en Facebook, con una breve descripción de éstas. Además, en el 100\% de los infográficos se distingue el logotipo de la empresa, aunque, varía de color, dependiendo del diseño de cada infográfico. En contraste, en ningún caso se agrega el vínculo electrónico a la publicación inicial en el sitio de la empresa.

En cuanto a la frecuencia de publicación de infográficos relacionados con el rol de la mujer, la Figura 4 deja ver que hay una tendencia por incrementar la cantidad de publicaciones sobre este rubro. No obstante, es claro que, en el periodo de un año, no siempre este tema es una opción para la empresa.

\section{Sobre la variable infografia}

Una de las variables de interés fue la infografía. De ella se evaluaron las partes de la estructura que tienen este tipo de publicaciones. En la Figura 5 se precisa más acerca de este elemento. Se observa que, 7 de cada 10 de los productos comunicativos analizados incluyen la estructura completa deseable para un infográfico.

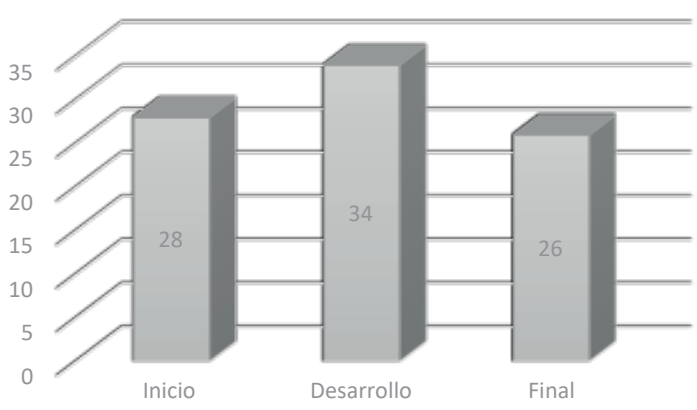

Figura 5. Partes de la estructura de la infografía que están presentes.

Fuente: Elaboración propia.

Por otro lado, los recursos visuales que prevalecen en el diseño de los infográficos censados son ilustraciones y la presentación de tiras cómicas -véase la Figura 6-. Estos recursos parecen ser el sello distintivo de la empresa.

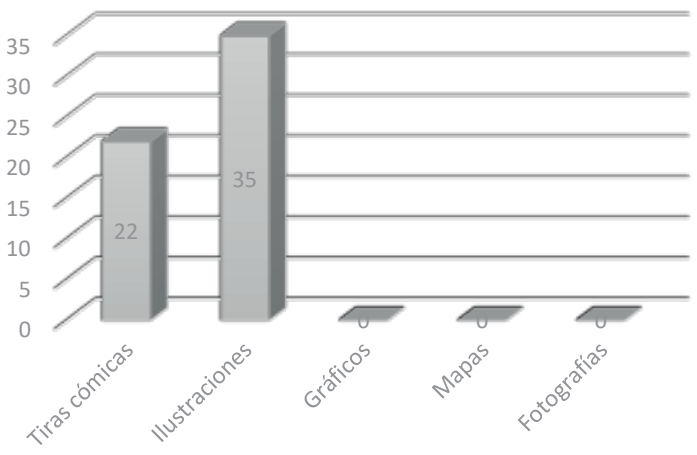

Figura 6. Elementos visuales que se ocupan en los infográficos evaluados.

Fuente: Elaboración propia.

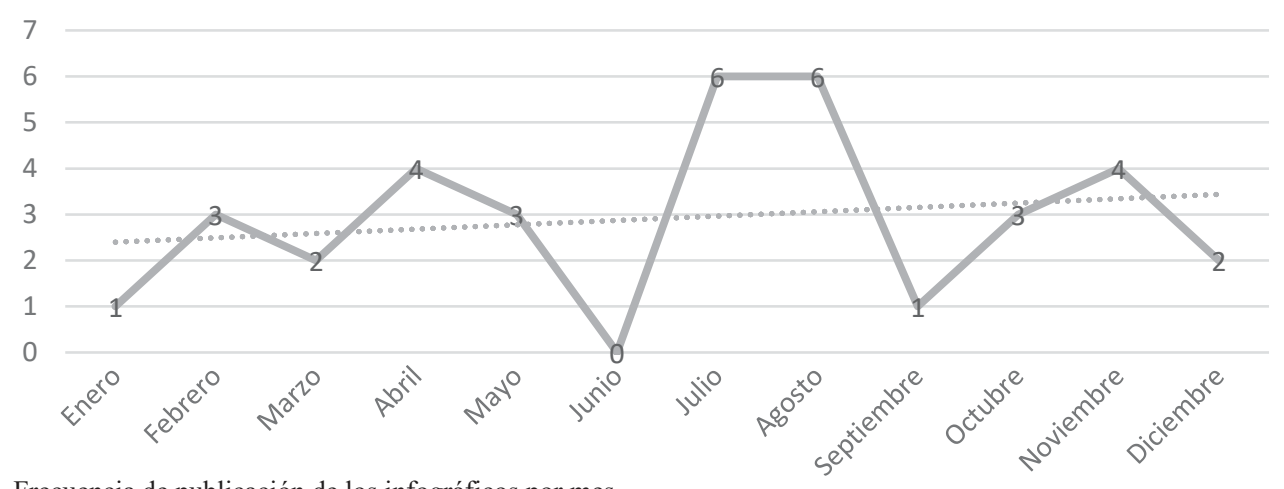

Figura 4. Frecuencia de publicación de los infográficos por mes. Fuente: Elaboración propia. 
Sobre el tono narrativo que se implementó en las infografías, prevalecen los tonos positivo y suave; sólo en algunos casos, el mensaje se enfoca en un tono de reclamo -17\%-. La concentración de estos datos se presenta en la Figura 7.

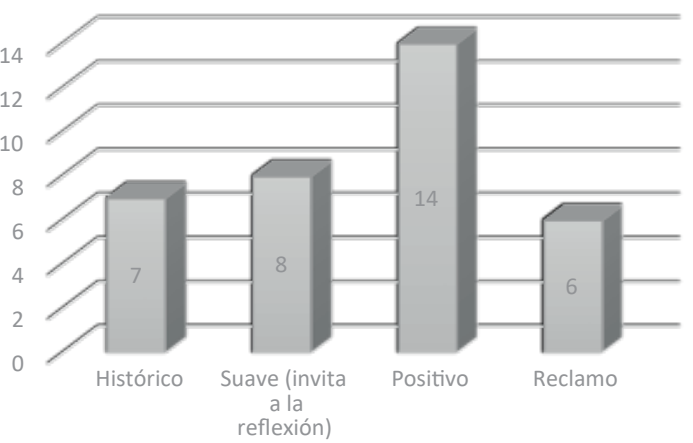

Figura 7. Tono narrativo que se utilizó en los infográficos muestreado.

Fuente: Elaboración propia.

Las problemáticas centrales de cada infografía fueron identificadas en esta investigación. En la Figura 8, deja ver que la desigualdad social, política y económica se representa con mayor frecuencia en los objetos de estudio que se observaron. No así, otras problemáticas como las desapariciones de mujeres, el acoso o los feminicidios.

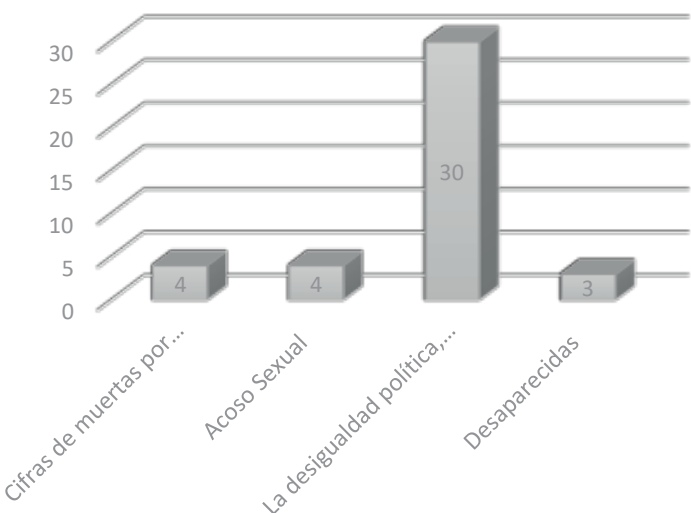

Figura 8. Problemáticas que se distinguen en los infográficos analizados.

Fuente: Elaboración propia.

Con respecto a las características

Tabla 1

Identificación de características esenciales de la infografía como producto comunicativo

\begin{tabular}{lc}
\hline \multicolumn{1}{c}{ Ítem } & Cumple \\
\hline Contiene la información novedosa sobre la temática abordada & $91.43 \%$ \\
Es clara y concisa & $100.00 \%$ \\
Se presenta la información de forma sintetizada & $91.43 \%$ \\
Se implementa un lenguaje asequible para el receptor & $100.00 \%$ \\
Se aprecia un título atractivo & $74.29 \%$ \\
Utiliza rótulos y/o tipografía distinta para dividir la información & $88.57 \%$ \\
Aparece el origen de la información que menciona & $88.57 \%$ \\
La tipografía utilizada facilita la lectura del infográfico & $97.14 \%$ \\
Incluye elementos visuales que apoyan la comprensión de la & $100.00 \%$ \\
temática & \\
Aporta conocimiento a los lectores & $77.14 \%$ \\
Se observa la información direccionada de forma adecuada para & $97.14 \%$ \\
su fácil lectura & $74.29 \%$ \\
Se visualizan datos reales y de reciente publicación & \\
Se utilizan como fuente de información, alguna de las siguientes: & \\
ONG, artículo científico, entrevista, biografía publicada, sitio & $85.71 \%$ \\
electrónico confiable, otro & \\
Se publica la fuente de información completa para que el usuario & $51.43 \%$ \\
la pueda consultar posteriormente & \\
\hline
\end{tabular}

Fuente: Elaboración propia. 
esenciales que contienen las unidades de estudio revisadas, en la Tabla 1 se enlista 15 de los elementos básicos que diversos autores (Zárate y Rodríguez-Rodríguez, 2017; Tejedor-Calvo et al., 2018; Arévalo, 2018; Ramos-Flores, 2019) coinciden debe integrar una infografía. De manera global, la empresa Pictoline genera infográficos que cubren en su mayoría con 14 elementos; lo anterior, en función de sus porcentajes mayores a 70\%.

\section{Sobre la variable Rol de la Mujer}

Otra de las variables de interés de esta investigación fue el Rol de la Mujer. Para su observación, se evaluaron elementos propios del proceso de comunicación. Por un lado, se delimitó que, por el tipo de recursos gráficos y diálogos que tiene el producto comunicativo, en el $49 \%$ de los casos, es una fémina quien narra o emite el mensaje central del infográfico.
Por otro lado, se estableció la temática o temáticas que se contenían en cada uno de los infográficos. Como se aprecia en la Figura 9, un $75 \%$ de los productos comunicativos abordan testimonios reales de mujeres como ejemplos de vida, esto se complementa con la difusión de los logros alcanzados por el género femenino. Al mismo tiempo, sobresale que las conmemoraciones no son un gran foco de interés para las publicaciones, ni temáticas relacionadas con la educación y prevención sexual.

Otro aspecto que se recuperó de los infográficos observados fue la forma en que la mujer es presentada. La Figura 10 destaca que, en casi la mitad de los productos comunicativos recuperados, la protagonista aparece sola; mientras que, en casi un tercio de las infografías aparece acompañada por otras mujeres. Destaca que tan solo en un caso, la figura

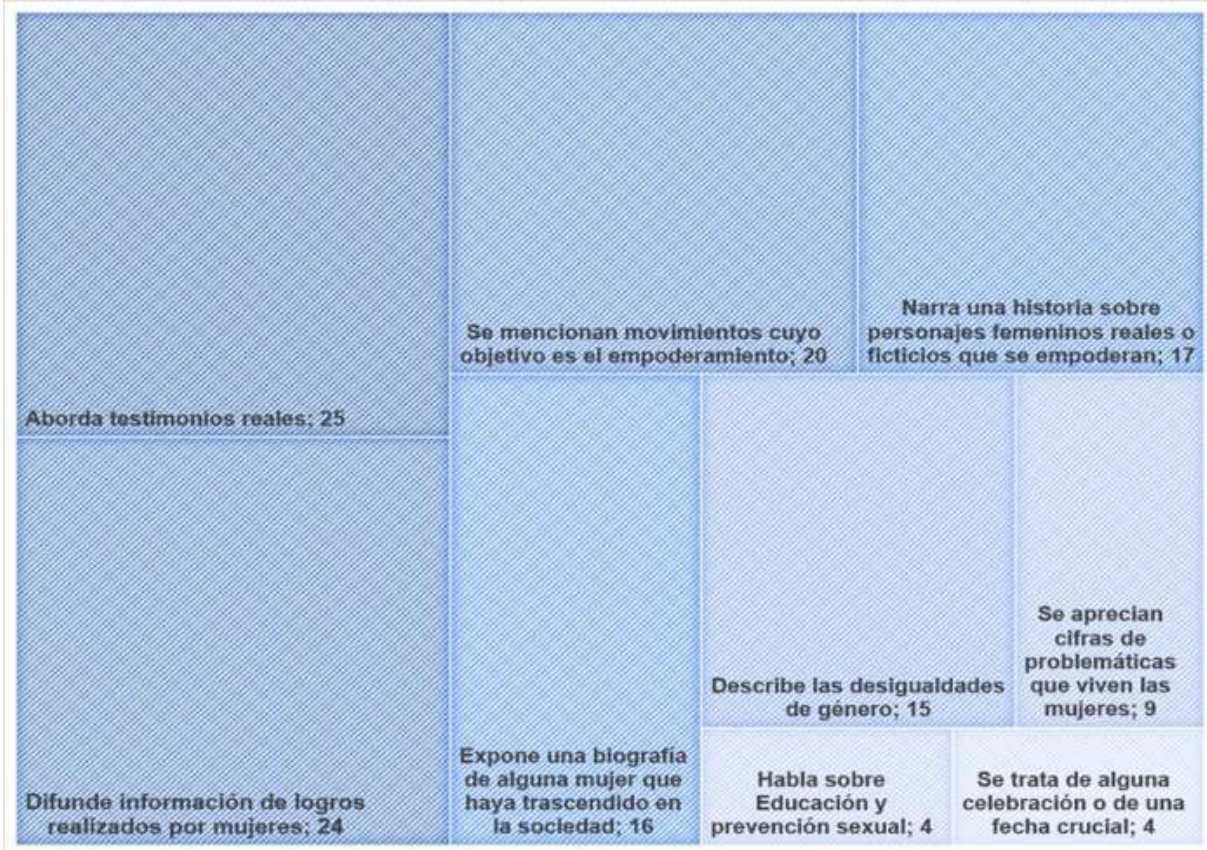

Figura 9. Temática sobre Rol de Género identificados en la infografía. Fuente: Elaboración propia. 
femenina se señala como personaje principal y aparece con personas de ambos géneros.

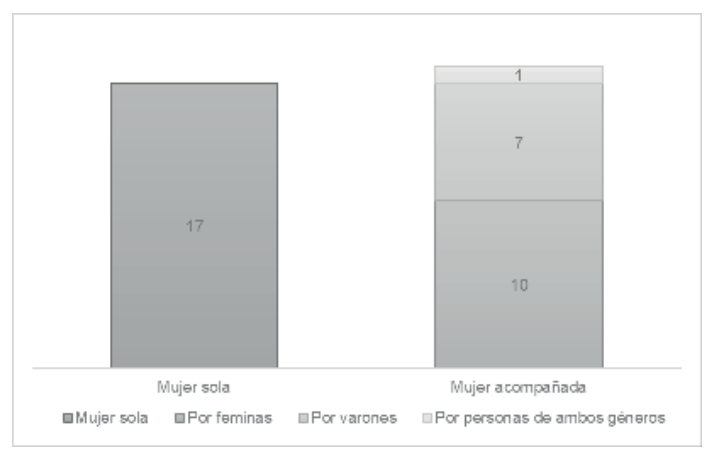

Figura 10. Presentación de la mujer en las infografías evaluadas

Fuente: Elaboración propia.

Adicionalmente, se revisó que en el contenido hubiera algún indicio sobre el movimiento feminista. En este sentido, la Tabla 2 destaca que no se aplicaron frases relacionadas al movimiento feminista. Aunado a ello, sólo en un porcentaje menor - $11 \%$ - se identifican simbología o colores asociados a este movimiento.

Como parte de los elementos que se refieren al feminismo, la observación de las infografías también implicó ubicar la presencia de concepto teóricos $\mathrm{o}$ definiciones de la teoría feminista como parte del mensaje que emite el producto comunicativo. Es así como, se identificó que las temáticas expuestas están relacionadas con el género en 6 de cada 10 productos visuales; en contraste, la
Figura 11 rescata que el sexismo y androcentrismo son temas poco abordados.

Dentro de esta investigación, se delimitó la intención del mensaje que se proyecta para el público sobre la mujer dentro del infográfico. La intención que es más recurrente en estos productos comunicativos es el reconocer y visualizar las aportaciones de las mujeres en la sociedad. En cambio, la idea de mencionar la importancia de que las mujeres incidan en la acción política colectiva fue poco tratada en estos elementos observados. La información procesada sobre esta categoría queda sintetizada en la Tabla 3.

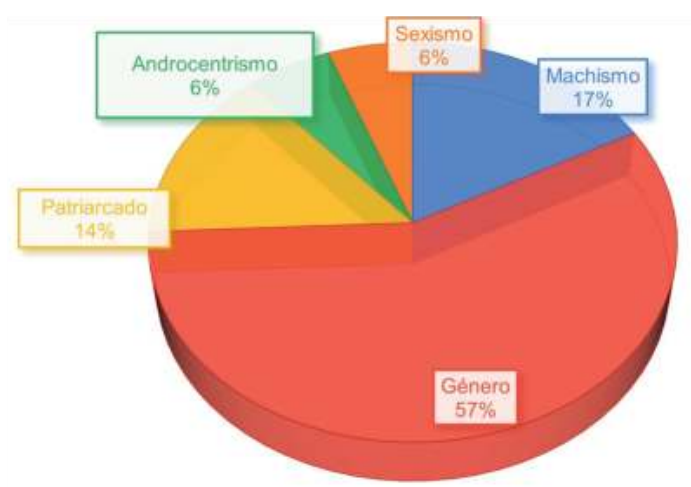

Figura 11. Presencia de conceptos teóricos/ definiciones de la teoría feminista.

Fuente: Elaboración propia.

La socialización e interacción que propician este tipo de infográficos es de llamar la atención. A partir del

Tabla 2.

Elementos que destacan de infográficos asociados al movimiento feminista

\begin{tabular}{lc}
\hline \multicolumn{1}{c}{ Ítem } & No se usa \\
\hline Principales frases del movimiento feminista & $100.00 \%$ \\
Simbología del movimiento feminista & $88.57 \%$ \\
Colores del movimiento: morado, verde & $88.57 \%$ \\
\hline
\end{tabular}

Fuente: Elaboración propia. 
procesamiento de datos se identificó que, en promedio, este grupo de infográficos se compartió 6736 veces; y todos estos elementos visuales al menos fueron compartidos una vez durante el año de análisis. Aunado a ello, la interacción entre los miembros de la red social deja ver un impacto medio en la población que observa los infográficos. De manera general, 4 de cada 10 cibernautas que comentan las publicaciones demuestran el interés o el impacto que les genera el producto comunicativo difundido por Pictoline; primordialmente, hay una tendencia por dar a conocer el entusiasmo que les genera el empoderamiento femenino. Estos resultados se describen con mayor precisión en la Tabla 4.

Tabla 3.

Intención que se distingue de manera general en el mensaje

\begin{tabular}{|c|c|}
\hline Ítem & Cumple \\
\hline $\begin{array}{l}\text { Promover la habilidad femenina para tomar decisiones en la vida y en la } \\
\text { de quienes las rodean }\end{array}$ & $48.57 \%$ \\
\hline Difundir los progresos realizados en favor de la igualdad & $28.57 \%$ \\
\hline Reconocer y visualizar las aportaciones de las mujeres & $68.57 \%$ \\
\hline $\begin{array}{l}\text { Hablar de la educación, la formación y el desarrollo profesional de las } \\
\text { mujeres }\end{array}$ & $42.86 \%$ \\
\hline $\begin{array}{l}\text { Señalar la importancia de aumentar el control, la eficiencia y la justicia } \\
\text { social a través de procesos participativos sociales }\end{array}$ & $54.29 \%$ \\
\hline Dar a conocer el impacto de que las mujeres tengan mayor autonomía & $45.71 \%$ \\
\hline $\begin{array}{l}\text { Mencionar la importancia de que las mujeres incidan en la acción política } \\
\text { colectiva }\end{array}$ & $8.57 \%$ \\
\hline $\begin{array}{l}\text { Subrayar el efecto que tiene el rol de la mujer en bienestar individual y } \\
\text { el desarrollo social }\end{array}$ & $34.29 \%$ \\
\hline \multicolumn{2}{|l|}{ Fuente: Elaboración propia. } \\
\hline \multicolumn{2}{|l|}{$\begin{array}{l}\text { Tabla } 4 . \\
\text { Efecto del mensaje en la interacción de los miembros de la red }\end{array}$} \\
\hline Ítem & Cumple \\
\hline Se comparten testimonios asociados a lo expuesto en la infografía & $45.71 \%$ \\
\hline Se comparte información que enriquece la publicación publicada & $40.00 \%$ \\
\hline $\begin{array}{l}\text { Se refleja entusiasmo por el empoderamiento femenino y el rol de } \\
\text { la mujer en los comentarios }\end{array}$ & $48.57 \%$ \\
\hline
\end{tabular}

Otro indicador que se observó sobre los infográficos asociado a la red social Facebook, son las reacciones que los cibernautas manifestaron. Es notorio que estos infográficos producen un alto impacto, generan conversación, pues de manera global dieron pie a más de 400,000 comentarios; lo que significa que cada infográfico tiene poco más de 11,900 reacciones en promedio. Esta aceptación se ve favorecida por el más de $80 \%$ de reacciones a favor que los infográficos tienen. La distancia entre datos mínimos y máximos es muy amplia, al igual que las desviaciones estándar; esto indica que, el homogénea en las infografías analizadas. comportamiento de las reacciones no es

Fuente: Elaboración propia. 
La distribución por tipo de reacciones se puntualiza en la Tabla 5.

Paralelamente, se registraron el número de comentarios y su intención, que los usuarios publicaron al pie del infográfico. En general, cada elemento visual promedia más de 3300 comentarios, y el $49 \%$ de éstos tienen un tono positivo. Sin embargo, se detectaron más comentarios negativos que neutros sobre los productos comunicativos. Cabe hacer mención que dichos comentarios negativos versaban en insultos, señalamientos sexistas o denigración del rol de la mujer. Los estadísticos que se obtuvieron se precisan en la Tabla 6 .

\section{Conclusiones}

La presente investigación tuvo por objetivo describir el uso de la infografía para difundir mensajes sobre el rol de la mujer en redes sociales por la empresa Pictoline. Este objetivo se alcanzó a partir de analizar las dos variables de interés, de las que surgen algunas relevantes deducciones.

Las infografías publicadas por Pictoline cumplen en gran medida con los

Tabla 5 .

Reacciones generadas por las infografías analizadas

\begin{tabular}{lccccc}
\hline Tipo de reacción & Total & Promedio & $\begin{array}{c}\text { Estadístico } \\
\text { Max }\end{array}$ & Min & $\begin{array}{c}\text { Desviación } \\
\text { estándar }\end{array}$ \\
\hline "Me divierte" & 8458 & 241.66 & 1800 & 0 & 409.09 \\
"Me asombra" & 7163 & 204.66 & 897 & 0 & 181.81 \\
"Me gusta" & 232500 & 6642.86 & 15000 & 1800 & 2869.85 \\
"Me encanta" & 115317 & 3294.77 & 9500 & 20 & 2279.99 \\
"Me enoja" & 17746 & 507.03 & 5500 & 0 & 1245.70 \\
"Me entristece" & 35474 & 1013.54 & 7200 & 0 & 1784.96 \\
\hline Total & $\mathbf{4 1 6 6 5 8}$ & $\mathbf{1 1 9 0 4 . 5 1}$ & & & \\
\hline
\end{tabular}

Fuente: Elaboración propia.

Tabla 6.

Comentarios generados por los miembros de la red social Facebook sobre el contenido de las infografías analizadas

\begin{tabular}{|c|c|c|c|c|c|}
\hline \multirow{2}{*}{ Tipo de comentario } & \multirow{2}{*}{$\begin{array}{c}\text { No. } \\
\text { Comentarios }\end{array}$} & \multirow[b]{2}{*}{ Promedio } & \multicolumn{2}{|c|}{ Estadístico } & \multirow[b]{2}{*}{$\begin{array}{c}\text { Desviación } \\
\text { Estándar }\end{array}$} \\
\hline & & & $\operatorname{Max}$ & Min & \\
\hline $\begin{array}{l}\text { Comentarios positivos } \\
\text { realizados por los } \\
\text { miembros en la red social }\end{array}$ & 57581 & 1645.17 & 1500 & 146 & 3126.57 \\
\hline $\begin{array}{l}\text { Comentarios negativos } \\
\text { realizados por los } \\
\text { miembros en la red social }\end{array}$ & 30834 & 880.96 & 9900 & 9 & 1903.89 \\
\hline $\begin{array}{l}\text { Comentarios neutrales } \\
\text { realizados por los } \\
\text { miembros en la red social }\end{array}$ & 27180 & 776.58 & 10500 & 24 & 1785.40 \\
\hline Total & 115595 & 3302.71 & & & \\
\hline
\end{tabular}

Fuente: Elaboración propia. 
elementos estructurales que autores como Bucchi y Saracino (2016), Tejedor Calvo et al. (2018), Arévalo (2018) y Rivera-Salas (2019) sugieren. Aunque, se requiere redireccionar el diseño de los títulos, pues en algunas ocasiones son poco llamativos, y de primera mano no resulta atractivo desde lo racional o lo emocional para el receptor, como lo comenta Aceves (2016). Lo anterior, puede disminuir la posibilidad de que la infografía sea vista por completo, y posteriormente socializada. Mas, al ser una empresa dedicada a la mercadotecnia, la publicación de estos contenidos visuales, le permite conocer y delimitar de forma óptima a las audiencias, lo que le puede generar beneficios en su propio campo de acción según lo aseveran Cohen et al. (2019) y Franch y Yeste (2017).

Hay que agregar que, en función de los temas que se socializan mediante los infográficos, estos productos resultan útiles para incrementar el bagaje cultural que los cibernautas tienen sobre el rol de la mujer. Se incluyen problemáticas sociales que más han afectado a la comunidad femenina en México y Latinoamérica; pero se abordan en un todo positivo con una intención más de informar y educar, que, de generar controversia, es decir, tienen un tono moderado-informativo más que beligerante y de contraste. De ahí que, las características que Aceves (2016) y Ramos-Flores (2019) señalan como relevantes para que un infográfico sea de contribución social se cumplen mayoritariamente en estos objetos de estudio analizados.
Por otro lado, el impacto de los infográficos en la red social Facebook es realmente significativo. Se vislumbra un alto nivel de interacción mediante la compartición de estos productos comunicativos. Igualmente, distintos receptores, destinan tiempo para evaluar el infográfico de forma positiva -con "Me gusta" o "Me encanta"-. Además, estos elementos gráficos generan una conversación en línea, en la que son protagonistas los seguidores de la empresa Pictoline, y cualquier otro usuario. Los comentarios que se emiten no sólo complementan la información expuesta, sino que proyectan la empatía por las historias y logros de mujeres abordadas, y se comparten testimonios de usuarias que han pasado por experiencias similares. En este sentido, se puede afirmar que estas infografías son eficientes en redes sociales, dados los parámetros de Fuster-Guillén et al. (2020) y Ozuna y Rivas (2014).

Es importante destacar que esta investigación se circunscribe al producto comunicativo llamado infografía y en el canal elegido -la red social Facebook-. La observación toma en cuenta de manera parcial la percepción del receptor sobre estos productos publicados en la red social especificada. Adicionalmente, sólo se verificó la presencia o ausencia de elementos vinculados con el rol de la mujer. Fue interés de este documento, cubrir únicamente el año 2019, que fue el periodo en que la ola feminista se presentó de manera muy significativa en México. No obstante, se precisa que, en futuras investigaciones se trabajen otros periodos y otras zonas geográficas, para 
lograr estudios comparativos que permitan ver la incidencia en otros planos y en otros niveles, del infográfico sobre este tema que es de dominio público.

Uno de los hallazgos realizados en esta investigación es que aún se presentan comentarios mal intencionados contra la mujer en general, más allá de un ataque a las protagonistas de las historias o hechos contados en las infografías, lo que nos habla de que aún hay mucho por difundir en estos temas para lograr una auténtica equidad de género y respeto. Por lo que, las autoras sugieren como futuros trabajos, el análisis del discurso en los mensajes derivados de las publicaciones que abordan algún tema de género. Otra de las líneas de investigación que se sugieren, es la valoración de las empresas como Pictoline, considerando la responsabilidad social que denotan y su contribución a la comunidad al abordar temas sensibles como el Rol de la Mujer.

Por último, las autoras consideran que es necesario desarrollar investigaciones de este tipo, pues permite a las organizaciones conocer a las audiencias digitales de redes sociales para diseñar mensajes más efectivos $\mathrm{y}$ estrategias de comunicación en el tema de empoderamiento de la mujer, sin importar si lo hacen con fines comerciales $o$ sociales, los estudios de esta índole son de utilidad para ambas aplicaciones.

\section{Contribución de autores}

P.E.R.S. Idea, revisión de literatura, metodología, análisis de datos, y redacción del artículo.
M.G.N.S. Revisión de literatura y redacción del artículo.

\section{Referencias}

Aceves, F. V. (2016). Infografías en pro de la equidad de género y empoderamiento de las mujeres: una revisión semiótica. Murmullos Filosóficos, 5(10). 55-72.

Aguilera, J. P., y Velazquez, B. (2017). La infografía en el periodismo audiovisual de Telecristal. Ponencia llevada a cabo en la 8va Conferencia Cientifica Internacional de la Universidad de Holguín, Holguín, Cuba.

Arévalo, J. Z. (2018). Infografía sobre el cáncer de cuello uterino y la percepción en las mujeres de 20-30 años en el Instituto Nacional Materno Perinatal del Perú, Lima-2018. (Tesis de grado). Universidad César Vallejo, Trujillo, Perú

Banda, A., Morales, M., y Vanegas, A. (2015). Hablando de empoderamiento: estudio de una muestra de género masculino en el noroeste de México. Revista de Psicología y Ciencias del Comportamiento de la U.A.C.J.S, 6(1), 86-99.

Bonavitta, P., De Garay, J., y Camacho, J. E. (2015) Mujeres, feminismos y redes sociales: acceso, censura y potencialización. Questión. Revista Especializada en Periodismo y Comunicación, 1(48), 33-44.

Bucchi, M., B., y Saracino, B. (2016). Visual Science Literacy' Images and Public Understanding ofScience in the Digital Age. Science Communication, 38(6), 812 -819. https://doi.org/10.1177/10755470 16677833

Castillo, S. (2019). Efecto del empoderamiento femenino sobre la nutrición infantil en Colombia. Sociedad y Economía, (36), 106-122. https://doi.org/10.25100/sye. v0i36.6037. 
Candale, C. V. (2017). Las características de las redes sociales y las posibilidades de expresión abiertas por ellas. La comunicación de los jóvenes españoles en Facebook, Twitter e Instagram. Colindancias: Revista de la Red de Hispanistas de Europa Central, (8), 201-218.

Cañedo-Cázarez, S., y Mendoza-Guerrero, J. M. (2017). Desplazamiento forzado y empoderamiento femenino: el caso de la presa picachos en el sur de Sinaloa, México. El Ágora USB, 17(2), 370-386. https://doi.org/10.21500/16578031.3279

Cohen, S., Dengate, J., Morrell, L., y Lee, K. (2019). Los medios de comunicación y las áreas protegidas. En Worboys G., Lockwood M., Kothari A., Feary S., y Pulsford I. (Eds.), Gobernanza y gestión de áreas protegidas. Bogotá, Colombia: ANU Press (pp. 467-500).

De Fontcuberta, M. (1994). Imagen, mujer y medios. Pensar las diferencias. Barcelona: Seminario Interdisciplinar Mujeres $y$ Sociedad, 149-178.

Fernández-Tijero, M. C. (2016). El origen de la mujer cuidadora: apuntes para el análisis hermenéutico de los primeros testimonios. Index de Enfermería, 25(1-2), 93-97.

Franch, P., y Yeste, E. (2017). Las redes sociales como herramienta para la divulgación de fondos documentales de bibliotecas. Estudio de caso de la cuenta en Twitter de la JFK Library. Investigación Bibliotecológica, 31(72), 21-37.

Fuster-Guillén, D. E., Serrato-Cherres, A., Gonzales, R., Goicochea, N. F., y Guillén, P. E. (2020). Uso de redes sociales en el desarrollo de estrategias de lectura crítica hipertextual en estudiantes universitarios. Propósitos y Representaciones, 8(1), 1-10. https://dx.doi.org/10.20511/pyr 2020.v8n1.432
Galván, M. (2019). 2019, el año en que la 'ola feminista' sacudió a México. Obtenido de https://politica.expansion.mx/sociedad/2 019/12/28/2019-el-ano-en-que-la-ola-fe minista-sacudio-a-mexico

Garavito, L. (2014). Retos y fortalezas del análisis de redes sociales aplicado al estudio de la movilización social por el agua en la cuenca de México. En Barraza, M., De Oca, L., y Londoño, D. (Eds.), Arenas de conflicto y experiencias colectivas: Horizontes utópicos y dominación. Ciudad de México: Colegio de México (pp. 443-484).

Guerrero, C., y Arana, I. (2019). Las primeras damas como miembros de la élite política. América Latina Hoy: Revista de Ciencias Sociales, (81), 31-49. https://doi.org/ 10.14201/alh2019813149

Herrero, V., F., y Rodríguez, A. M. (2015). Periodisme de dades, infografia i visualització de la informació : un estudi de El País, El Mundo, Marca i El Correo. BiD: textos universitaris de biblioteconomia i documentació, (34), 1-7.

Lashew, C. H. (1975). A quantitative approach to content validity. Personnel Psychology, 28 (4), 563-575. https://doi.org/10.1111/ j.1744-6570.1975.tb01393.x

López, A. C., Valencia, O. D., y Díaz, H. H. (2019). Política pública y procesos de empoderamiento femenino. Un estudio del Proyecto Estratégico de Seguridad Alimentaria en Santa Lucía Miahuatlán, Oaxaca. Aposta. Revista de Ciencias Sociales, (81), 38-53.

Martínez, S. (2017). Procesos de empoderamiento y liderazgo de las mujeres a través de la sororidad y la creatividad. Dossiers Feministes, (22), 49-72. http://dx.doi. org/10.6035/Dossiers.2017.22.4

Ozuna, N., y Rivas, C. (2014). La libertad de escoger desde las redes sociales: 
reflexiones desde la realidad paraguaya. Revista da Faculdade de Direito da UFG, 38(2), 195-229. https://doi.org/10.5216/ rfd.v38i2.34606

Pérez, L., Rábago, M., Guzmán, M., y Zamora, R. (2018). Sororidad en los procesos de envejecimiento femenino. Diversitas, 14(1), 13-26. https://doi.org/10.15332/ s1794-9998.2018.0001.01

Pictoline. (2020a). Nadie es demasiado pequeño para lograr un cambio. Obtenido de Pictoline https://img.pictoline.com/2019/ 12/cbnTtu3VvsyJ7iaPpqP10MClYOPrhn fck4wY9n7E.png

Pictoline. (2020b). Mujeres al poder. Obtenido de Pictoline https://www.facebook.com/pic toline/photos/a.1611821172410355/2850 251031900690

Ramos-Flores, M. A. (2019). Infografía sobre violencia contra la mujer y la percepción visual en alumnos de I.E. de Cercado de Lima, Lima - 2019. (Tesis de grado). Universidad César Vallejo, Trujillo, Perú.

Ramírez, C., Martínez, L. M., y Calderón, L. K. (2016). Capital Social y Empoderamiento en mujeres para disminución de pobreza en Colombia. Revista Venezolana de Gerencia, 21(76), 693-708.

Real Academia Española. (2021). Feminismo. Obtenido de https://dle.rae.es/feminismo

Redacción Gatopardo. (2019). Las mujeres sacudieron a México. Obtenido de https://gatopardo. com/noticias-actuales/el-movimiento-fe minista-sacudio-a-mexico-este-2019/

Rivera-Salas, P E. (2019). Infografías de salud publicadas por organizaciones y autoridades sanitarias en la red social Pinterest. Revista de Investigación en Tecnologías de la Información, 7(13), 92-100.

Saldanha, P. A., y Gonçalves, H. S. (2016). Prácticas de empoderamiento feminino na América Latina. Revista de Estudios Sociales, (56), 80-90. https://dx.doi.org/10.7440/res56. 2016.06

Sancho, F. J. (2021). Sobre la politización de las mujeres. Desde la perspectiva de Edith Stein. Crítica, (1063), 20-25.

Statista. (2020). Redes sociales con el mayor porcentaje de usuarios en México en 2019. Obtenido de https://es.statista. com/estadisticas/1035031/mexico-porcen taje-de-usuarios-por-red-social/

Tejedor-Calvo, S., Portalés-Oliva, M., y Pueyo, S. (2018). Web 2.0 y tratamiento informativo en las principales revistas españolas de divulgación científica y de la pseudociencia. Revista Latina de Comunicación Social, (73), 293-316. http://dx.doi.org/10.4185/ RLCS-2018-1256

Velandia, F. (2016). Mujeres activas: actoras sociales y políticas, una experiencia desde la Iniciativa Local de Paz de Facatativá-Cundinamarca. Aletheia, 8(1), 136-160.

Zárate, F. J., y Rodríguez-Rodríguez, M. F. (2017). La infografía digital como dispositivo didáctico y de evaluación de narrativas personales. Una experiencia de animación sociocultural en equidad de género. Congreso Internacional de Educación y Evaluación 2016, 2(2). 